\title{
A Study Of Sustaining Firm Competitive Advantage Through Its Image
}

\author{
Steven X. Si (E-mail: ssi@bloomu.edu), Bloomsburg University of Pennsylvania, USA \\ Liu Ren-Huai (E-mail: lrh@jnu.edu.cn), Jinan University, China (PRC) \\ Pamela Wynn (E-mail: pwynn@bloomu.edu), Bloomsburg University of Pennsylvania, USA \\ Mainuddin, Afza (E-mail: mafza@bloomu.edu), Bloomsburg University of Pennsylvania, USA
}

\begin{abstract}
A mass of literature exists promoting the benefits of resource-based theory of the organization. This literature suggests that business-level resources may be sources of competitive advantage if they are rare, valuable, nonsubstitutable, and difficult to imitate. Unfortunately, applying this theory to research or practice requires that the study first identify specific resources that can be measured and investigated. It also requires that this study develops and tests separate theories to explain how these resources are related to competitive advantage. Only through these steps will this study be able to extend the resource-based view of the organization in explaining and affecting competitive advantage efforts. The overarching theory (i.e., resource-based theory) provides only a useful guide to identifying important resources and relationships. The current study argues that organization image is one such resource. The ability of this resource is to enhance an organization competitive advantage. Furthermore, the tacitness, complexity, and specificity characterized by organization image can make this advantage sustainable.
\end{abstract}

\section{Introduction}

Much strategy literature has focused on the concept of competitive advantage (e.g., Bain, 1956; Barney, 1986, 1991; Porter, 1980, 1985). One popular view of competitive advantage, the resource-based view of the organization, suggests that an organization has a potential advantage if it possesses distinctive competencies that give it a benefit over its competitive opponents (Lado, Boyd, \& Wright, 1992; Lippman \& Rumelt, 1982; Reed \& DeFillippi, 1990). The primary interest in this line of research lies in determining how a competitive advantage may be established and subsequently sustained. An explicit assumption is that organizations can generate economic rents (i.e., returns earned by the most efficient users of capital in an industry) by employing resources that are valuable, rare, imperfectly imitable, and nonsubstitutible (Barney, 1986). It has also been argued that in a gradually evolving environment organizations must reinvest in such resources in order to sustain the advantage (Aaker, 1989; Dierickx \& Cool, 1989; Reed \& DeFillippi, 1990). Thus, the objective of researchers and managers must be one of identifying, accumulating, and developing valuable resources that generate causal ambiguity and maintain or increase barriers to imitation. The result is a sustained competitive-advantage.

While general theoretical discussions in this area have been numerous and some efforts have addressed types of resources (Miller \& Shamsie, 1996), little effort has been given to understanding the relationship between specific, identifiable resources and sustained competitive advantage (for an exception see Powell, 1992). If this approach is to be extended, and managers are to be able to identify resources in which to reinvest, it seems necessary to investigate specific resources that may act as sources of sustainable competitive advantage. The current paper discusses one such resource - organization image. The current study proposes that organization image is a valuable resource that can produce economic rent through its effect on business risk and expect profit, and because of its causally ambiguous nature and the difficulty of acquiring it from a factor market organization image has the potential to be a sustainable source of competitive advantage. 
This paper is generally organized into three sections. First, this study defines organization image and describe the characteristics that are thought to be a source of advantage. Specifically, image is conceptualized as a perception-based business-level resource that is affected by tangible and intangible factors. In addition, organization image is thought to have an effect on other business resources (e.g., organization culture) that can also lead to a competitive advantage. While the study conceptualizes image as a business-level resource possessed by single businesses or corporate units that operate as autonomous businesses, there may be implications for the image construct in the domain of corporate-level strategy, but these issues are specifically omitted from this discussion. As Rumelt (1985) has suggested, business-level activity explains much of the variance in performance while the corporate level explains very little. Thus, image may be useful for understanding achievement of corporate-level objectives other than performance, but because our focus is on understanding competitive-advantage differences the current study will leave the corporate-level discussion for another time. In the second section this study introduces theory to support the tacitness, complexity, and specificity of the organization image construct. While organization image has been treated as a potential source of a competitive advantage, the sustainability of that advantage is contingent upon the causal ambiguity of the resource, which effectively raises barriers to imitation by competitors. Because image is a perception-based construct, progress in this area requires the identification of the organization's stakeholders and an understanding of the factors that affect their image perceptions. Support is offered from marketing literature that has investigated the effects of the image construct attached to other referents, such as country-of-origin and product brand names (e.g., Han, 1989). The current study concludes that an organization's image is a resource that can resist erosion by competition because of barriers that make imitation difficult. The nature of its characteristics and formation give organization image the tacitness, complexity, and specificity, which is necessary for organization to make its competitive advantage sustainable. In the third section this study summarizes our conclusions about imagebased advantages and offer suggestions for future research and practice. Specifically, the current study proposes that organization image is an identifiable resource that can be investigated and affected by the actions of organizational decision-makers, while remaining difficult to imitate by the organization's competitors.

\section{Organization Image}

The role of image in economic activities was first discussed by Kenneth Boulding in the middle 1950s (Lindquist, 1975). He theorized that human behavior is not entirely directed by explicit knowledge and information, but is also the product of perceived images. Since that time, image research has been extended to politics and countries (e.g., Han, 1989); to consumers, users, and stores (McDougall \& Fry, 1975); to products and services (Keller, 1993; Nagashima, 1977; Ofir, 1986); and to organizations and management (Dierickx \& Cool, 1989; Lindquist, 1975). Of particular relevance to this discussion, recent management literature has begun to shed light on the positive effects of organization image (Dutton \& Dukerich, 1991; Gatewood, Gowan \& Lautenschlager, 1993; Dutton, Dukerich \& Harquail, 1994; Miller \& Shamsie, 1996; Fombrun, 1997; Rindova \& Fombrun, 1998).

In general, these efforts suggest that organization image should be considered a multidimensional construct that refers to individuals' ratings of an organization's various attributes. These dimensions can be classified into tangible and intangible factors that seem to affect image perceptions and serve as a means of understanding the causally ambiguous nature of the construct. The other conclusion the current study can draw from the uses of this term is that image is a construct that can be attached to different referents (e.g., organization, brand, country-of-origin) and can be identified for different constituencies (e.g., the employees' image of the organization, external stakeholders' image of the organization). Marketing literature that has addressed such topics as brand image and country-oforigin effects on consumer behavior provides a good basis for conceptualizing the image construct and understanding the factors that might affect an organization's image (e.g., Jaffe \& Nebenzahl, 1984; Keller, 1993). In general, image is conceptualized as the physical and psychological meaning assigned to a specific referent. For our purposes, the major point to gather from this area of study is that image results from individuals' attempts to assign meaning to past experiences, and that this meaning affects future behavior. As such, image is derived through the perception-based interaction of the referent (e.g., the organization's attributes), the individual perceiver and the situation. Thus, while this complex interaction suggests that image cannot be directly manipulated by the organization, it does identify the specific factors that must be studied (i.e., the organization, the individual perceiver, and the situation) and the process by which an image is derived (i.e., a perception process). 
One theory of perception formation and perception-driven behavior, attribution theory, suggests that a fundamental human process is making sense of a complex environment (Kelley, 1956). Causal inferences about past behavior provide the basis for future actions by the individual forming the perception (Mowday, 1983). Thus, according to this theory, individuals perform a backward-reasoning process to form perceptions that will subsequently determine their future responses toward the referent of the attributions. Regarding organization image, this theory would suggest that stakeholders will form a positive or negative image of the organization based on their perceptions of the organization's past behaviors and the environmental situations that surround those behaviors, and the nature of the image perception will drive their future responses toward the organization. Also, an attribution view of organization image suggests that image is a relatively stable construct. That is, when individuals are asked to report their image of an organization their report will be based on the series of attributions that have occurred over time from their previous interactions with the organization (Lord \& Smith, 1983). Individuals are said to assign meaning for past outcomes or behaviors to one of four general causes (i.e., the ability or effort of the referent, the difficulty of the task, or luck). This suggests that attributions may be assigned to internal (e.g., the organization) or external (i.e., the environment) causes and to stable (e.g., ability) or unstable (e.g., effort) causes. For example, if when an organization is faced with a crisis its stakeholders perceive that the cause of the crisis is the ability or effort of the organization their response will be different than if they had attributed the cause to an external source, such as bad luck. Or if an organization's many past successes are attributed to external causes (luck, timing, industry effects) while its few failures are attributed to internal causes (e.g., effort or ability) the organization may have an overall low image despite a generally positive reputation created by a large number of successes and only a few failures.

Thus, from the information outlined above this study can conclude that image is a forward-looking construct that is based on the perceptual processes of individuals, the past actions of the organization, and the situation surrounding those actions. As such, image is the sum of individuals' evaluative judgments about the relevant organizational attributes and contains an expectancy type judgment about the future. It is this construct that is theorized to affect the opportunity to generate economic rent and provide the ability to sustain such advantage.

\section{A Source Of Competitive Advantage}

The importance of organization image is tied to its ability to produce a competitive advantage. This ability can be seen through at least three avenues. First, organization image as formed by the judgments of the organization's employees (and potential employees) is important because it represents these individuals' best guess at what characteristics non-members are likely to ascribe to them on the grounds of their organizational affiliation (Crocker $\&$ Luthanen, 1990). Thus, at the very least, organization image is an important component of a company's ability to attract, develop, and keep talented people (Gray, Jr. 1986). Image may also influence employees' performance through its ability to affect the amount and type of motivation employees exhibit (Crocker \& Luthanen, 1990; Dutton \& Dukerich, 1991) or the activities they choose to direct attention toward (for example, image affects impression management behaviors - Dutton \& Dukerich, 1991). In addition, organization image may overlap with another resource (i.e., organization culture) that meets the three conditions of valuable, rare, and imperfectly imitable characteristics necessary to attain a competitive advantage (Alvesson, 1990; Barney, 1986; Fiol, 1991). As with image, culture is a valuable resource that is intangible. The loose coupling between an organization's tangible attributes and its image also exists between observable artifacts of an organization's culture and the meaning that is assigned to those artifacts by its members. In addition, managing culture successfully seems to require an ability to manipulate identities (i.e., characterizations of an individual in relation to a larger referent) rather than explicit behaviors (Fiol, 1991). Because organization image is a perception about a specific referent to which individuals may identify (i.e., the organization), it may be that that organization image is a part of organization culture or interacts with culture in determining behaviors. Thus, one method by which image leads to a competitive advantage is through its affect on other valuable organization resources.

A second issue that reinforces the importance of image as an organization-relevant construct is the link between an organization's objectives and the behaviors of constituencies who may be targets of efforts directed at achieving those objectives. Gray \& Smeltzer (1985), for example, suggest that the effectiveness of a strategic effort is contingent upon the image held by the target of the strategy (e.g., customers). Specifically, they say that a "negative image perceived by any of the company's publics indicates either an inappropriate strategy or a failure to com- 
municate that strategy effectively" (Gray \& Smeltzer, 1985, p. 73). Others (e.g., Alvesson, 1990) state that image 'management' is important toward any target group who's attitudes have some level of "significance for an organization" (p. 377). Thus, the success of any given strategy is contingent upon the perceptions held by those the organization wishes to attract or affect.

Finally, the image held by external stakeholders who have the power to affect opportunities available to the organization and the specific levels of risk and expected profit associated with each opportunity. Actions that lead to a positive image held by this constituency will decrease the risk and increase the expected return through the possibility of increasing the number of opportunities available to organization decision-makers. Similar to the effect of increasing trust in a relationship, the current study suggests that changes in image decrease the uncertainty associated with interaction with the organization. Organizations with negative images will be at a competitive disadvantage because of the lower number of opportunities available to them and the accompanying relatively higher risk and lower return combinations of those that are available.

Thus, the above evidence suggests that organization image is a potentially valuable resource through its ability to interact with other organization resources, through its ability to affect the success of a strategic effort to an organization. If this study assumes that managers understand the relationship between inputs and their organization's image better than their competitors, organization image may be a resource that can be used to an organization's competitive advantage.

\section{Sustaining The Advantage}

In addition to its ability to create a competitive advantage, the nature of organization image is such that the advantage may be sustainable because its complexity, tacitness, and asset specificity create barriers to imitation by competitors. Reed and DeFillippi (1990) have suggested that a resource must possess these three characteristics if it is to provide a sustained advantage. Otherwise, competitors may be able to erode a one-time advantage.

One defining feature of organization image is its high degree of complexity. Image is not easy to change and the relationships between factors that affect it are not completely clear (Alvesson, 1990). No matter how hard public relations personnel try to depict their organization in a certain fashion, people often see something else (Sauerhaft \& Atkins, 1989). Similar to impression management that deals with the ability of individuals to affect the perceptions people have about them, organization image cannot be easily manipulated by a few directed behaviors. Rather, image is a relatively stable, perception-based construct that is affected by both the characteristics of the perceiver, the characteristics and behaviors of the organization, and the situation (Alvesson, 1990). This does not mean that organization image is not changeable, only that it is a complex construct that is not easy to manipulate.

Organization image also exhibits a high degree of tacitness. That is, organization image cannot be directly obtained or 'seen' and is only acquired through a process of 'building by doing' (for a discussion of a similar topic i.e., tacit knowledge - see Polanyi, 1966; Reed \& DeFillippi, 1990). Organization image is developed over time through the actions of the organization, and the manner in which factors interact to affect the image is not clearly understood. In the words of Dierickx and Cool (1989), the tacit nature of image classifies organization image as a "stock" resource, acquired and maintained only by a constant "flow" of inputs. For an organization with no image, or a negative image, time and considerable effort must be directed at developing a positive image. It cannot be purchased directly. Consider, for example, two organizations with identical public relations expenditures, but significantly different images. The difference is reflected in the underlying stock of image inputs that have been accumulated over time, not the current level of expenditures. The organization with the image advantage uses its expenditures to maintain the advantage. Thus, without considerable effort the disadvantaged organization will be unable to close the gap.

Tacitness can also be seen in the intermix of tangible (i.e., functional) and intangible (psychological) attributes that affect organization-image perceptions (Lindquist, 1975). While it is convenient to distinguish between tangible and intangible attributes, the difference is not always clear and these attributes must be judged 
through a perception process further blurring the distinction and thus adding to the high degree of tacitness. Consider, for example, the dimensions of a specific product's image. A product engineer may classify technological data about a product as tangible, while to the average non-engineer, all such data merely contributes to a mystique (i.e., an intangible attribute of the product's image). Also, it may be that organization image is based as much on a lack of information as on explicit facts reported about the organization (Ofir, 1986). Together these characteristics of organization image and the image-formation process help us conclude that organization image exhibits a high level of tacitness.

Finally, image is characterized by a high level of asset specificity. Because image is a 'stock' resource and because it is specific to the organization to which it is attached, it can not be easily earned, purchased, or transferred (Dierickx \& Cool, 1989). The current study suspects that even buying an organization may not allow for a direct transfer of its image. That is, the image is not likely to remain intact under new ownership. The factors surrounding the acquisition and the image of the purchasing organization or the new ownership group are likely to interact with the existing image to produce new perceptions about the purchased organization. Earning a positive image, or reducing a negative image, requires time and a continuous flow of inputs and events and is directly tied to the specific individuals and events associated with these input flows. Thus, it can be concluded that organization image, through its high degree of tacitness, complexity, and specificity, provides the potential for a sustained competitive advantage.

\section{Conclusions And Implications}

This paper has focused on how organization image can lead to a competitive advantage and make this advantage sustainable. Organization image is a potentially valuable resource through its ability to interact with other organization resources and its ability to enhance an organization's competitive advantage. If the study assumes that managers understand the relationship between inputs and their organization's image better than their competitors (Note: it is not necessary to understand the relationship completely; only better than the competitor), organization image may be a resource that can be used to an organization's competitive advantage. Likewise, the tacitness, complexity, and asset specificity characterized by organization image make this potential advantage sustainable.

Future effort directed at the topic of organization image should proceed on a number of major fronts. First, effort should focus in the area of measurement. By developing instruments to measure organization image it will then be possible to investigate the factors that affect it. The current study suspects that in many cases organization members will find that others' perceptions of the organization image will differ from their own, and that different stakeholder subgroups, in and outside the organization, will have different perceptions, as well.

The development of measurement instruments may be aided by image studies from other domains (e.g., Jaffe \& Nebenzahl, 1984), but must include both tangible and intangible attributes that are used to form image perceptions. "Tangible" refers to such organization elements as product, service, and personnel. It also refers to qualities that can be more or less objectively compared with those of a competition. "Intangible" refers to psychological attributes, such things as a sense of belonging, the feeling of warmth or friendliness, or possibly a feeling of excitement or interest (Lindquist, 1975).

It has also been suggested that the effect of certain factors on organization image may be contingent upon other factors (Alvesson, 1990). Alvesson has pointed out that image is a perception that is formed in the absence of close contact with an object, and that the role of any given attribute or management effort in affecting the image depends upon the availability of other information to the stakeholder group. For example, if the organization is large and the executive management team is largely unavailable for direct contact with stakeholders, image perceptions about the management group may be largely affected by advertising or other public relations activities. On the other hand, if the company is a small local organization with a CEO who is active in community events and philanthropic organizations, perceptions may be largely unaffected by public relations activities. Thus, the same characteristics that make this a potential source of competitive advantage make measurement of the construct a challenge to researchers and practitioners alike.

Finally, because image is a perception-based construct, progress in this area also requires the identification of the organization's stakeholders and an understanding of the factors that affect their image perceptions. Assistance 
can be found in marketing literature that has investigated the effects of the image construct attached to other referents, such as country-of-origin and product brand names, from attribution literature that helps explain how perceptions are affected (Kelley, 1956; Mowday, 1983), and possibly from leadership theory (Yukl \& Van Fleet, 1992) that attempts to explain how individuals (e.g., subordinates) might come to trust and respect a specific referent (i.e., a leader). These areas of study help us conclude that the image construct has implications for the behaviors of individuals relevant to the organization's success, and offer suggestions on specific directions for studying the factors that affect organization image.

\section{References}

1. Aaker, D. A. (1989). "Managing assets and skills: The key to a sustainable competitive advantage", California Management Review, Winter, 91-106.

2. Aaker, D. A., \& Jacobson, R. (1987). "The role of risk in explaining the differences in profitability", Academy of Management Journal, 30, 277-296.

3. Alvesson, M. (1990). “Organization: From substance to Image?”, Organization Studies, 11, 3, 373-394.

4. Bain, J.S. (1954). "Economies of scale, concentration and the condition of entry in twenty manufacturing industries", American Economic Review, 44: 15-39.

5. Barney, J. (1986). “Organizational culture: Can it be a source sustained competitive advantage?”, Academy of Management Review, 11, 3, 656-665.

6. Barney, J. (1991). "Organization resource and sustained competitive advantage", Journal of Management, 17, 99-120.

7. Crocker, J. \& Luthanen, S. R. (1990). "Collective self-esteem and in-group bias", Journal of Personality and Social Psychology, 58, 60-67.

8. Dierickx, I. \& Cool, K. (1989). "Asset stock accumulation and sustainability of competitive advantage", Management Science, 35, 1504-1511.

9. Dutton, J. E. \& Dukerich, J. M. (1991). "Keep an eye on the mirror: Image and identity in organizational adaptation", Academy Management Journal, September, 547-549.

10. Dutton, J. E., Dukerich, J. M. \& Harquail, C. V. (1994). “Organizational Image and Member Identification", Administrative Science Quarterly, 39, 239-263.

11. Fiol, C.M. (1991). "Managing culture as a competitive advantage: An identity-based view of sustainable competitive advantage", Journal of Management, 17, 191-211.

12. Fombrun, C. J. (1997). Reputation: Realizing Value from the Corporate Image, Cambrige, MA: Harvard Business School Press.

13. Gatewood, R. D., Gowan, M. A. \& Lautenschlager, G. J. (1993). "Corporate image, recruitment image, and initial job choice decisions", Academy of Management Journal, 36, 414-427.

14. Gonner, E. C. K. (1891). Ricardos political economy. London: George Bell and Sons.

15. Gray, JR., J. G. (1986). Managing the corporate image. Westport, Conn: Quorum.

16. Gray, E.R./Smeltzer, L. R (1985). “Corporate Image - An Integral Part of Strategy", Sloan Management Review, Summer, 1988, pp. 73-78.

17. Han, C. M. (1989). “ Country image: Halo or summary construct?”, Journal of Marketing Research, 26, 247-252.

18. Harrington, D. R. (1983). Modern portfolio theory \& the capital asset pricing model. Englewood Cliffs, NJ: Prentice-Hall.

19. Holmes, J. G. \& Rempel, J. K. (1989). "Trust in close relationships", In C. Hendrick (Ed.), Close relationship, 187-220. Newbury Park, CA: Sage.

20. Jaffe, E. D. \& Nebenzahl, I. D. (1984). "Alternative questionnaire formats for country image studies", Journal of Marketing Research, 21, 463-471.

21. Keller, K. L. (1993). "The effects of corporate branding strategies on brand equity", Advances in Consumer Research, 20, 27.

22. Lado, A.A., Boyd, N.G., \& Wright, P. (1992). "A competency-based model of sustainable competitive advantage: Towards a conceptual integration", Journal of Management, 18: 77-91.

23. Lindquist, J. D. (1975). "Meaning of image", Journal of Retailing, 50, 29-38. 
24. Lippman, S.A. \& Rumelt, R.P. (1982). "Uncertain imitability: An analysis of inter-organization differences in efficiency under competition", Bell Journal of Economics, 13: 418-438.

25. Lord, R.G. \& Smith, J.E. (1985). "Theoretical, information processing, and situational factors affecting attribution theory models of organizational behavior", Academy of Management Review, 8, 1, 50-60.

26. Markowitz, H. M. (1952). "Portfolio Selection", Journal of Finance, March, 77-91.

27. McDougall, G. H. G. \& Fry, J. N. (1975). "Combining two methods of image measurement", Journal of Retailing, 50, 53-61.

28. Miller, D. \& Shamsie, J. (1996). "The resource-based view of the organization in two environments: The Hollywood film studios from 1936 to 1965", Academy of Management Journal, 39, 3, 519-543.

29. Mowday, R.T. (1983). "Viewing turnover from the perspective of those who remain: The relationship of job attitudes to attributions of the causes of turnover", Journal of Applied Psychology, 66, 1, 120-123.

30. Nagashima, A. (1977). "A comparative 'made in' product image survey among Japanese businessmen", Journal of Marketing, July, 24-37.

31. Ofir, C. (1986). "Measuring images of foreign products", Columbia Journal of World Business, Summer, 105.

32. Peteraf, M. A. (1993). "The cornerstones of competitive advantage: A resource-based view", Strategic Management Journal, 14, 179-191.

33. Polanyi, M. (1966). The tacit dimension. Garden City, NY: Doubleday.

34. Powell, T.C. (1992). "Strategic planning as competitive advantage", Strategic Management Journal, 13, 551-558.

35. Reed, R. \& DeFillippi, R. J. (1990). "Causal ambiguity, barriers to imitation, and sustainable competitive advantage", Academy of Management Review, 15, 88-102.

36. Rindova, V. \& Fombrun, C. J. (1998). "Constructing Competitive Advantage", Strategic Management Journal.

37. Rumelt, R.P. (1982). "Diversification strategy and profitability", Strategic Management Journal, 3: $359-369$.

38. Sauerhaft, S. \& Atkins, C. (1989). Image Wars. New York: John Wiley \& Sons.

39. Sawyer, G. (1990). Business policy and strategic management. HBJ, Publishers.

40. Schoemaker, P. (1990). "Strategy, complexity, and economic rent", Management Science, 36, 1178-1192.

41. Webber, A. M. (1993). "What's so new about the new economy?", Harvard Business Review, 20, 24-41. 
Notes 